\title{
Relationship between Social Networking Platforms and Performance of Virtual Teams in Nigeria Telecommunication Industry
}

\author{
Fasanmi, Samuel Sunday ${ }^{1} \&$ Ogunyemi, A.O. ${ }^{1}$ \\ ${ }^{1}$ Department of Psychology, Olabisi Onabanjo University, Ago-Iwoye, Ogun State, Nigeria \\ Correspondence: Fasanmi, Samuel Sunday, Department of Psychology, Olabisi Onabanjo University, \\ Ago-Iwoye, Ogun State, Nigeria
}

Received: December 4, 2017

Accepted: January 20, 2018

Online Published: January 24, 2018

doi:10.5539/ijps.v10n1p30

URL: http://doi.org/10.5539/ijps.v10n1p30

\begin{abstract}
The study examined a relationship between social networking platforms and performance of virtual teams in Nigeria telecommunication industries. Opinions of one hundred and eleven virtual team members from three giant telecommunication firms in Enugu and Lagos, Nigeria participated in the study.MTN Nigeria, Globacom Nigeria and Airtel Nigeria were sampled using self-designed questionnaire. Two research hypotheses were tested. It was found out that that there was a significant relationship between types of social networking platforms used (Facebook, Skype, MySpace, Instagram. and Linked) in the workplace on performance of virtual teams $\left\{\mathrm{X}^{2}(2)\right.$ $=211.108 ; \mathrm{p}<.05\}$. Regression results indicated that the overall model fit five predictors (types of organization, team membership, job position, social networking platforms, and sex) was questionable $(-2$ Log Likelihood $=$ 92.683 ) but was statistically reliable in distinguishing between virtual team performances $X^{2}(5)=54.352, p$ $<.05)$. Useful recommendations that would enhance a synergy between virtual team members and healthy social network platforms were suggested.
\end{abstract}

Keywords: Job performance, Social Networking Platforms, Telecommunications, and Virtual Teams

\section{Introduction}

Virtual teams are groups of dispersed individuals who rely on communication and information technologies to interact. These teams exist solely because of the technologies that support their interactions. However, they are an interesting organizational form as they allow organizations to connect disparate experts and key employees without the related costs in travel and disruptions to business. Much research has examined the nature of virtual teams, with a major interest in improving virtual team interactions and subsequent performance. Virtual teams are somewhat unique in that the very technologies that support their existence are often the same source of problems and concern (Fuller and Summers, 2017).

Given the almost exclusive need to communicate via computer-mediated methods, virtual teams have several unique characteristics that influence the degree to which they can be productive and successful, and even supersede face to face teams. A major inhibitor or facilitator of virtual team success in interactions is the development of shared identity which helps in the creation of common language, expectations, and processes by which virtual teams can improve productivity and performance.

Over the past several decades, there has been a geometric increase in organizations' use of virtual teams for ease of work and this trend is seeping seamlessly into the future. In a survey conducted by (Culture Wizard, 2016), it was found out that out of 1372 business respondents from 80 countries. $85 \%$ of the respondents worked on virtual teams and $48 \%$ reported that over half their virtual team members were members of other cultures. Such significant growth is not unconnected to factors such as globalization, distributed expertise, organizations' need for rapid product development and innovation, and improved networking and collaboration technologies that support e-collaboration (Ilgen, Hollenbeck, Johnson, \& Jundt, 2005; Kozlowski \& Bell, 2003; Mathieu, Maynard, Rapp, \& Gilson, 2008).

Dulebohn and Hoch (2017) opined that the use of virtual team structures holds great promise as virtual teams can do things collectively that collocated teams cannot. Virtual team has great advantages such as: the ability to assemble teams that maximize functional expertise by including professionals who are geographically dispersed, enabling continuous all round productivity by using different time zones to their advantage, lowering costs by 
reducing travel, relocation and overhead, and sharing knowledge across geographic boundaries and organizational units and sites. Despite these advantages, virtual teams present a number of challenges compared to co-located teams. Some disadvantages include communication and collaboration difficulties, low levels of media richness compared to co-located teams, potentially lower team engagement by team members, distrust, and shared responsibility among team members, isolation, high levels of social distance between members, and challenges in monitoring and managing virtual teams.

Although, social networking platforms can be served as an important tool to create competitive advantage (Riemer \& Tavakoli, 2013), it may play double-edged roles (Turban, Bolloju, \& Liang, 2011). Specifically, social networking platforms can be used to facilitate knowledge management and problems-solving, which are beneficial to increase workflow rate in organisations. However, social networking platforms may decrease productivity because of misuse and personal chat (van Zyl, 2009). This indicates that the value of social networking platforms is dependent on how the tools are utilized (Majchrzak, Cherbakov, \& Ives, 2009). Thus, it is expedient to explore the influence of different social networking platforms use on team performance.

Alternative workplaces are embraced as organizations seek to improve group and team efficiencies. Organizations find they are able to increase the speed of work, to enhance the transfer of information between people and across organizations, and to exploit information gathering, analysis, and dissemination processes. The results include cost savings (e.g., reduced overhead), increased productivity, and retention of talented employees in the workplace (Apgar, 1998).

The explosion of cyberspace technology and methods of scheduling work takes organizational structures in new directions, making virtual teams a reality. Certainly the technology itself is an important aspect of virtual team processes. Improved information technology is often the way by which individuals communicate with one another in a virtual team. Organizations have used technology (e.g., electronic meetings) for years to promote brainstorming and enhance group processes (Kahai, Sosik, \& Avolio, 1997; Townsend, Whitman, \& Hendrickson, 1995). "Managing a productive virtual team [however] requires more than access to technology" (Kimball \& Eunice, 1999, p. 58).

Boyd \& Ellison (2007) observed that social networking sites are web-based services that allow individuals to construct a public or semi-public profile within a bounded system, articulate a list of other users with whom they share a connection, and view and traverse their list of connections and those made by others within the system. In the same vein, Helou and Rahim (2010), were of the opinion that online social networks (OSNs) is a virtual communities which allows for people to connect, relate, and interact with one another on a particular subject of discuss together online. No doubt, social media sites around the world are good platforms for users with a number of options to interact through entertainment, chats, gossips, and other social activities. Through these social network platforms, individuals are able to interact with each other on various workplace issues.

There are umpteenth popular social network platforms on mobile and web applications, these include: Facebook, Twitter, YouTube, Whatsapp, Instagram, snap chat, Google Plus etc. Each of the platform thrives in its uniqueness, and also have specific roles, functions and modes of communication. It is to be noted however that the fuvtions of these platforms are mostly related. This relates to the definition by Kaplan and Haenlein (2010), who defined social media as "a group of Internet-based applications that build on the ideological and technological foundations of Web 2.0, and that allow the creation and exchange of user-generated content". Ayiah and Kumah (2011), summed up the definition of social network as a web platform where people from different settings can connect and interact with each other.

Communication technologies usually deployed to support dispersed teams include e-mail, computerized conferencing, telephone conferencing and videoconferencing. These communication technologies allow organizations to form virtual teams by dissolving the boundaries that separate members. One objective of using SNP's is to create comparable levels of communication, speed and effectiveness as those achieved at traditional face to face meetings. Social networking platforms examined in the study include Facebook, Skype, Twitter, MySpace, and Instagram.

According to Internet usage statistics for the world, there were 3,885,567,619 estimated Internet users with a penetration rate of $51.7 \%$ as at June, 2017. Also, the estimated population of Africa in 2017 was 1,246,504,865 of which $388,376,491$ were Internet users. The penetration of Internet on the continent was $31.2 \%$. By June, 2017, the number of Facebook users in Africa was 160,207,000. In Nigeria, the number of internet users as at July 2017 was 91,598,757 with 47.7\%Internet penetration. (Internet World Statistics, 2017).

With the Internet revolution, the information world has not remained the same, especially with regard to sharing, speed, storage and retrieval of information in whatever form regardless of the person's location. Through the 
Internet a number of web technologies emerged, and one technology that is making waves with regard to information sharing and communication are the social media networks. The evolution of social media has cut across all facets of society with its positive and negative impacts. Social media has transformed and impacted on communication, learning, research and education in general. Among the vast variety of online tools which are available for communication, social networking sites (SNS) have become the most modern and attractive tools for connecting people throughout the world (Aghazamani, 2010).

Over the last decade, a major stream of research, especially in developed countries, has sought to assess performance of teams more generally. Virtual team performance has become a topical issue in today's business environment, so much so that organizations go to great lengths to appraise. Performance in teams has been a precursor that determines whether the teams are healthy or not.

Virtual teams have also been the subject of considerable research attention which has yielded interesting insights on the drivers of different dimensions of performance. However, our knowledge on the topic remains fragmented and not well integrated. For instance, researchers have investigated the effect of factors such as Trust (Paul et al., 2004) and conflicts (Mortensen et al., 2001). Research has also been conducted to understand the effect of computer- mediated communications (Adres 2002). In this day and age, face-to-face interaction among team members is becoming an old form of production (Lipnack \& Stamps, 2000). As a development, corporations make use of SNP's to mediate communications among teams whose members are geographically dispersed. The present study sets out to determine if the performance of virtual teams can be improved by the use of social networking platforms.

Virtual work settings in telecommunication industries may cause some organizational challenges such as maintaining remote leadership, managing cultural differences, and developing trust relationships among the teams. According to Staples, \& Zhao (2006), other challenges suggested that global virtual teams need to deal with such as communication difficulties, decreased cohesion, and high level of conflicts among teams. Indiramma and Anandakumar (2009) were of the opinion that the handling of technological issues such as adaptation and regular use of communication tools as another challenge that faces global virtual teams. Those challenges may pose a threat to the performance of any global virtual teams. However, the problem can be more perceptible in support teams in which troubleshooting customers' technical problems is inherently complex and challenging (Williamson, Bauer, Steinberg, Mislevy, Behrens and DeMark, 2004); Cavaiani, 2005).

Troubleshooting in virtual environment involves communication with remote customers and collaborating with other global virtual teams, which introduces a new layer of challenges to support teams. Customers and support professionals have to collaborate to make the troubleshooting process succeed. Leaders of support organizations need to overcome the challenges of distributed settings to resolve technical problems and satisfy their customers (Oussamaand Gholam, 2014). Oussama and Gholam, (2014) also identified factors such as communication tools, cohesion and collaboration, leadership, trust, the location of team members and team size. The peculiarity of Nigerian factors bothering on electricity and political instability could also pose serious challenge to the effectiveness of virtual team performance.

This study, therefore, is aimed at filling a knowledge void by assessing the extent to which the use of SNP's in the workplace influences performance of virtual teams in organizations

Therefore, the present study will provide answer to this question; will there be a positive significant relationship between the use of social networking platforms in the workplace and performance of virtual teams?

From the forgoing, two hypotheses were formulated.

$\mathbf{H}_{\mathbf{1}}$ : The use of Social Networking Platform (SNP) will have significant influence on performance of virtual teams in the workplace.

$\mathbf{H}_{2}$ : Type of organization, team membership, job position, social network platform and sex, will significantly predict performance of virtual teams.

\section{Research Method}

\subsection{Research Design}

The survey method was used for the study. The responses were sampled with the use of a well-structured questionnaire. The demographic variables used in the research include age, sex, marital status, and educational qualification. Social networking platforms were used as independent variable while performance of virtual teams was used as dependent variable. 


\subsection{Population of the Study}

The research population comprised of all the workers of MTN Nigeria, Globacom Nigeria and Airtel Nigeria who were virtual team members.

\subsection{Participants}

A total of one hundred and twenty virtual team members from three giant telecommunication firms in Nigeria participated in the study. From the 120 questionnaires administered, 50 copies went to MTN, 35 copies to Airtel and 35 copies to Globacom. These firms were selected because the use of virtual operations was common and inherent in the organizations as they have the facilities, the technology and the expediency to provide their services to the satisfaction of their teeming customers round the clock. The retrieved questionnaires were one hundred and eleven comprising forty-four participants 44(39.6\%) from MTN, thirty-three participants 33(29.7\%) from Airtel and thirty-one participants $31(27.9 \%)$ from Globacom while responses on questionnaire not indicating any of the three firms were $2(1.8 \%)$. Also, $75(67.6 \%)$ are male while $36(32.4 \%)$ are female.

\section{Instruments}

The research used a standardized questionnaire to obtain data from respondents. Virtual Team Scale by Lurey \& Raisinghani (2000) was used and four (4) items measured performance of virtual teams with a likert scale ranges from 1-5 with Strongly Agree (5), Agree (4), Not Applicable (3), Disagree (2), and Strongly Disagree (1). Example of items include: "The team is currently meeting its business objectives, "When the team completes its work, it is generally on time", "When the team completes its work, it generally within budget", and "So far the team has been effective in reaching its goals". A template questionnaire by Jstor.com was adopted in measuring SNP use in the workplace. It consisted of a 7-item inventory designed to measure use of SNP in the workplace. The section A was for demographic data which include age, sex, marital status and educational experience. The section B includes the four items measuring virtual team performance.

\section{Validity and Reliability of Instrument}

The virtual team instrument has a Cronbach's Alpha reliability of 0.82 as reported by Lurey and Raisinghani (2000). However, a total item correlation was done to ascertain the reliability of the scale. The new scale has a Cronbach Alpha reliability of .557.

\section{Procedure}

Copies of questionnaire were sent to the selected firms after approval of the management of these firms had been obtained. The process involved filling of questionnaires by virtual team members. The participants were adequately informed that the distributed questionnaires were for research purposes and that response from them would be treated with utmost confidence. The questionnaire was administered for a period of 3 weeks.

\section{Method of Data Analysis}

Chi Square analysis was used to establish relationship between the variables while logistic regression analysis was also used to test the second hypothesis.

\section{Results}

Hypothesis one states that there will be a significant relationships between types of social networking platforms used in the work place and performance of virtual teams 
Table 1. Summary of Chi Square Test of Independence showing the relationship between types of social networking platforms used in the workplace on performance of virtual teams

\begin{tabular}{|c|c|c|c|c|c|c|}
\hline \multirow[t]{2}{*}{ Types of SNP Used } & \multicolumn{2}{|c|}{ Performance } & \multirow[t]{2}{*}{ Total } & \multirow[t]{2}{*}{$\mathrm{X}^{2}$} & \multirow[t]{2}{*}{ df } & \multirow[t]{2}{*}{$\mathrm{P}$} \\
\hline & Low & High & & & & \\
\hline \multicolumn{7}{|l|}{ Facebook } \\
\hline Did not use Facebook & 263 & 138 & 401 & & & \\
\hline Used Facebook & 239 & 114 & 353 & & & \\
\hline Total & 502 & 252 & 754 & & & \\
\hline \multicolumn{7}{|l|}{ Twitter } \\
\hline Did not use Twitter & 191 & 111 & 302 & & & \\
\hline Used twitter & 213 & 99 & 312 & 211.108 & 2 & $<.05$ \\
\hline Total & 404 & 210 & 614 & & & \\
\hline \multicolumn{7}{|l|}{ Skype } \\
\hline Did not use Skype & 161 & 102 & 263 & & & \\
\hline Used Skype & 187 & 94 & 281 & & & \\
\hline Total & 358 & 196 & 544 & & & \\
\hline \multicolumn{7}{|l|}{ MySpace } \\
\hline Did not use MySpace & 13 & 14 & 27 & & & \\
\hline Used MySpace & 43 & 14 & 57 & & & \\
\hline Total & 56 & 24 & 84 & & & \\
\hline Linked in & Low & High & & & & \\
\hline Did not use Linked in & 65 & 21 & 86 & & & \\
\hline Used Linked in & 117 & 21 & 138 & & & \\
\hline Total & 182 & 42 & 224 & & & \\
\hline Instagram & Low & High & & & & \\
\hline Did not use Instagram & 36 & 18 & 54 & & & \\
\hline Used instagram & 69 & 24 & 93 & & & \\
\hline Total & 105 & 32 & 147 & & & \\
\hline Others & Low & High & & & & \\
\hline $\begin{array}{l}\text { Did not use other social } \\
\text { networks }\end{array}$ & 41 & 12 & 53 & & & \\
\hline Used other social networks & 50 & 16 & 66 & & & \\
\hline Total & 91 & 28 & 112 & & & \\
\hline
\end{tabular}

Table 1 reveals that there is a significant relationship between types of social networking platforms used in the workplace on performance of virtual teams $\left\{\mathrm{X}^{2}(2)=211.108 ; \mathrm{p}<.05\right\}$. Thus hypothesis which states that there will be a significant relationship between type of social networking platform used and performance of virtual teams is confirmed. The table revealed that use of Facebook in the workplace is significantly related to low performance. It could be as a result of online distractions during work hours like chat from friends, notifications on wall etc. Where internet is available for free, a worker might want to take a sneak pick into his Facebook profile on the go during work hours and this in turn might hamper performance. Twitter use in the workplace also has a significant relationship with performance but in a negative way, showing low performance(213) and high performance (99) It could also be as a result of the afore mentioned possibilities. The table also shows that use of Skype has an influence on performance but in a negative way, indicating frequency for low performance as (187) and for high (94). It was also revealed that use of MySpace have a negative influence on performance, 
with low performance frequency (43) and high (14). Linked in also shows a negative influence on performance with frequency for low performance (117) and for high (21) indicating a negative influence of the use of linked in. The table reveals that instagram use in the workplace has a negative influence on performance with a frequency on low performance as (69) and high performance (24). The table also revealed that other SNPs have a negative influence on performance.

Hypothesis two states that type of organization, team membership, job position, social network platform and sex, will significantly predict performance of virtual teams.

Table 2. Summary of Regression Analysis showing the influence of mental health and psychological well-being on Authoritative Styles

\begin{tabular}{llllll}
\hline Variables & $\beta$ & Wald & $\mathrm{df}$ & $P$ & Odds Ratio \\
\hline Type of organization & -3.241 & 8.768 & 1 & .003 & .039 \\
Team-membership & 5.117 & 15.139 & 1 & .000 & 166.909 \\
Job position & -.143 & .108 & 1 & .742 & .867 \\
Social networking platforms & -.143 & .399 & 1 & .528 & .866 \\
Sex & 4.195 & 1.551 & 1 & .007 & 66.376 \\
\hline
\end{tabular}

Logistic regression was conducted to determine which independent variables (types of organization, team membership, job position, social networking platforms, and sex) are predictors of virtual team performance. Regression results indicated that the overall model fit five predictors (types of organization, team membership, job position, social networking platforms, and sex) was questionable $(-2 \log$ Likelihood $=92.683)$ but was statistically reliable in distinguishing between virtual team performances $\left.\mathrm{X}^{2}(5)=54.352, p<.05\right)$. The model correctly classified only $72.5 \%$ of the cases. Regression coefficients are presented in Table 2 . Wald Statistics indicated that types of organization, team membership, and sex predict virtual team performances. However, odd ratios for these variables indicated little change in the likelihood of virtual team performances.

\section{Recommendations}

The research showed that there was a negative relationship between social networking platforms and performance of virtual teams. This could be as a result of distractions that stems from chat between online friends and family members while on a task or possible loss of non- verbal cues in the process of handling and transfer of messages from one location to another via these social networking media.

In line with the findings of the research, it is recommended that online monitoring and evaluation should be introduced to checkmate team members who lost out of the job at hand to chat pleasantries and online gaming or even visiting dating sites in the middle of a task.

It is recommended that during the initial formation of virtual teams, team members should meet face to face, so as to familiarize with one another. This would go a long way in bridging cultural barriers and to a certain level enhance trust among team members. From time to time, there should be face to face interactive sessions, such as team building/ bonding exercises and social interaction avenues.

The results revealed sex as not being a predictor of performance. Therefore sexual discrimination in the workplace should be discouraged and job opportunities should be given to the best hands irrespective of their gender.

Educational qualification is not a predictor of performance based on the results revealed by the study. Therefore working in a virtual environment requires a substantial knowledge in operating the communication tools and various social networking mediums.

\section{References}

Apgar, M. (1998). The alternative workplace: Changing where and how people work. Harvard Business Review, 76(3), 121-136.

Ayiah, E.M. \& Kumah, C.H. (2011). Social networking: a tool to use for effective service delivery to clients by African Libraries. Available at: http://conference.ifla.org/past-wlic/2011/183-ayiah-en.pdf (accessed 2 September, 2017). 
Boyd, D. M., \& Ellison, N. B. (2007). Social network sites: Definition, history, and scholarship. Journal of Computer-Mediated Communication, 13(1), 210-230. https://doi.org/10.1111/j.1083-6101.2007.00393.x

Bradener, E.G. Mark, \& T. D. Hertel. (2005). Team size and Technology Fit: Participation Awareness, and Rapport in Distributed Teams. IEEE Transaction of Professional Communication, (48)1, 68-77. https://doi.org/10.1109/TPC.2004.843299

Cavaiani, T.P. (2005). Using selected options of the Ipconfig command to teach network trouble shooting techniques. Journal of Information Systems Education, 16(3), 251-254.

Dulebohn, J.H., \& Hoch, J.E. (2017). Virtual teams in organizations. Human Resource Management Review. https://doi.org/10.1016/j.hrmr.2016.12.004

Fuller R. M., \& Summer, J. D. (2017). The Impact of Virtual Team Consistency on Individual Performance and Perceptual Outcomes Over Time. Proceedings of the 50th Hawaii International Conference on System Sciences. https://doi.org/10.24251/HICSS.2017.095

Griffith, T.L., J.E. Sawyer \& M.A. Neale. (2003). Virtualness and Knowledge in Teams: Managing the Love Triangle in Organizations, Individuals, and Information Technology. MIS Quarterly, 27, 265-287. https://doi.org/10.2307/30036531

Ilgen, D. R., Hollenbeck, J. R., Johnson, M., \& Jundt, D. (2005). Teams in organizations: From input-process-output models to IMOI models. Annual Review of Psychology, 56, 517-543. https://doi.org/10.1146/annurev.psych.56.091103.070250

Indiramma, M.M., Anandakumar, K.R. (2009). Behavioral analysis of team members in virtual organization based on trust dimension and learning. Proceedings of World Academy of Science: Engineering \& Technology, 39(3), 269-274.

Internet World Statistics. (2017). Retrieved from Usage and Population Statistic: internetworldstats.com/stats1.htm.

Isheriff. (2010). Strategies for managing social networking and personal web use in the workplace. Costa Mesa, CA: Isheriff.

Kahai, S. S., Sosik, J. J., Avolio, B. J. (1997). Effects of leadership style and problem structure on work group process and outcomes in an electronic meeting system environment. Personnel Psychology, 50, 121-146. https://doi.org/10.1111/j.1744-6570.1997.tb00903.x

Kimball, L., \& Eunice, A. (1999). The virtual team: Strategies to optimizes performance. Health Forum Journal, $42(3), 58-62$.

Kozlowski, S. W. J., \& Bell, B. S. (2003). Work groups and teams in organizations. InW. C.Borman, D. R. Ilgen, \& R. J. Klimoski (Eds.). Comprehensive handbook of psychology, industrial and organizational psychology (pp. 333-375). New York, NY: John Wiley. https://doi.org/10.1002/0471264385.wei1214

Majchrzak, A., Cherbakov, L., \& Ives, B. (2009). Harnessing the power of the crowds with corporate social networking tools: How IBM does it. MIS Quarterly Executive, 8(2), 103-108.

Mathieu, J., Maynard, M. T., Rapp, T., \& Gilson, L. (2008). Team effectiveness 1997-2007: A review of recent advancements and a glimpse into the future. Journal of Management, 34, 410-476. https://doi.org/10.1177/0149206308316061

Oussama, S., \& Gholam, S. A. (2014). Factors affecting virtual teams performance in telecommunication support environment. Telematics and Informatics, 2, 459- 462.

Riemer, K., \& Tavakoli, A. (2013). The role of groups as local context in large Enterprise Social Networks: A Case Study of Yammer at Deloitte Australia. Working Paper.

Staples, D.D., Zhao, L. (2006). The effects of cultural diversity in virtual teams versus face-to-face teams. Group Decision \& Negotiation, 15(4), 389-406. https://doi.org/10.1007/s10726-006-9042-x

Townsend, A., Whitman, M. \& Hendrickson, A. (1995). Computer support system adds power to group processes. HR Magazine, 40(9), 87-91.

Turban, E., Bolloju, N., \& Liang, T.-P. (2011). Enterprise Social Networking: Opportunities, Adoption, and Risk Mitigation. Journal of Organizational Computing and Electronic Commerce, 21(3), 202-220. https://doi.org/10.1080/10919392.2011.590109 
van Zyl, A. S. (2009). The impact of Social Networking 2.0 on organisations. The Electronic Library, 27(6), 906-918. https://doi.org/10.1108/02640470911004020

Williamson, D.M., Bauer, M., Steinberg, L.S., Mislevy, R.J., Behrens, J.T., DeMark, S.F. (2004). Design rationale for a complex performance assessment. International Journal of Testing, 4(4), 303-332. https://doi.org/10.1207/s15327574ijt0404_2

\section{Copyrights}

Copyright for this article is retained by the author(s), with first publication rights granted to the journal.

This is an open-access article distributed under the terms and conditions of the Creative Commons Attribution license (http://creativecommons.org/licenses/by/4.0/). 